\title{
Mannose-Binding Lectin 2 Gene Polymorphism during Pandemic: COVID-19 Family
}

\author{
Tufan Tukek $^{1}$ Sacide Pehlivan ${ }^{2}$ Yasemin Oyaci ${ }^{20}$ \\ ${ }^{1}$ Department of Internal Medicine, Faculty of Medicine, Istanbul \\ University, Istanbul, Turkey \\ 2 Department of Medical Biology, Faculty of Medicine, Istanbul \\ University, Istanbul, Turkey \\ ${ }^{3}$ Department of Physiology, Faculty of Medicine, Istanbul University, \\ Istanbul, Turkey \\ Glob Med Genet 2022;9:185-188.
}

Ummuhan Isoglu-Alkac ${ }^{3}$

\begin{abstract}
Keywords

- COVID-19

- mannose-binding lectin 2

- polymorphism
\end{abstract}

\author{
Address for correspondence Yasemin Oyaci, MSc, Department of \\ Medical Biology, Faculty of Medicine, Istanbul University, Turgut Ozal \\ Millet Cad., 34093 Fatih, Istanbul, Turkey \\ (e-mail: yaseminf@hotmail.com).
}

\section{Introduction}

Coronavirus disease 2019 (COVID-19) is a pandemic that has infected many people since the first case was announced and has been among the major infectious events of the century. Individuals older than 65 years and patients with comorbid burden have a mortal course. ${ }^{1-3}$

Specifically, detecting host-based factors that predispose to infection constitutes a very important research area. In this context, one of the different host factors can be mentioned from the literature: Mannose-binding lectin 2 (MBL2) is a serine protease belonging to the collectin family and is believed to be an important factor in the inherited immune system. The MBL2 protein binds to the surface of a wide range of microorganisms by its ability to recognize or function directly as an opsonin or through activation of the complement system, therefore increasing the phagocytosis of microorganisms by macrophages and neutrophils. ${ }^{4}$ There are several known polymorphisms in the MBL2 gene

received

December 9, 2021

accepted

December 29, 2021 (10q21.1), located on the long arm of chromosome 10, in both the promoter and exon regions, resulting in multiple haplotypes. These genetic polymorphisms are associated with different levels of MBL expression and activity. ${ }^{4,5}$ Various studies on the association of MBL2 genetic polymorphism and/or MBL plasma levels with severe infections, sepsis, and septic shock have shown an increased risk of developing sepsis in patients with MBL deficiency and a negative outcome.,

Medetalibeyoglu et al investigated the clinical effect of the MBL2 (rs1800450) gene variant in a total of 284 COVID-19 cases. $^{7}$ The BB genotype of the MBL2 gene was found to be more common among COVID-19 cases compared with healthy controls. The risk of severe disease (odds ratio [OR] $=5.3, p<0.001)$ and intensive care unit (ICU) requirement $(\mathrm{OR}=19.6, p<0.001)$ were revealed to be higher for $\mathrm{BB}$ genotype. On the other hand, no significant difference was found between genotype variants in terms of 28-day mortality or secondary bacterial infection development.

(C) 2022. The Author(s).

This is an open access article published by Thieme under the terms of the Creative Commons Attribution License, permitting unrestricted use, distribution, and reproduction so long as the original work is properly cited. (https://creativecommons.org/licenses/by/4.0/)

Georg Thieme Verlag KG, Rüdigerstraße 14, 70469 Stuttgart, Germany 


\section{Methods and Results}

In this article, the MBL2 ( $r s 1800450)$ genetic polymorphism was analyzed using the same method, and we present a COVID-19 family of five patients that was proven in parallel with main study. ${ }^{8}$ A written consent was obtained from all patients for both sampling and publishing.

The COVID-19 family consisted a total of five members: a 56-year-old father, a 51-year-old mother, two sons aged 23 and 21 years, and a 15-year-old daughter. The father does not have any comorbidities. He was taken to home for isolation on April 2, 2020, after the polymerase chain reaction (PCR) sample was taken in the emergency department, where he presented with symptoms related to upper respiratory tract. Among the PCR samples taken from all patients, only he was positive. On April 7, 2020, all samples were taken again and 23-year-old son was positive. The samples of all family members, together with the father, who admitted to the emergency department on April 9, 2020, with dyspnea and refractory fever, were repeated. The father was hospitalized in the ICU to be followed up with a noninvasive mechanical ventilator in the picture of multi-inflammatory syndrome- adult (MIS-A) with respiratory failure findings. Despite bilateral diffuse lung involvement, the mother without any known comorbidity was taken to the ward due to her vital parameters and clinical stable status. The PCR result taken in the emergency department was positive. The 23-year-old son was hospitalized with bilateral diffuse lung infiltration in the MIS-A picture in ICU. Repeated PCR test is also positive. Of the other two children, the 21-year-old son also showed bilateral lung infiltration, but was only isolated in hospital. The PCR test result was positive. On the other hand, the first PCR test taken in the emergency department of the 15-yearold daughter was negative, but it was decided to be followed up in the hospital due to high risk of contact, and the test repeated 2 days later was found to be positive. The father received anticytokine and anticoagulant treatment during the ICU follow-up; he was discharged after 10 days. The mother and the 23-year-old son were discharged after 7 days with only anticoagulant and supportive treatment, while the 21-year-old son and the 15-year-old daughter were followed up with home isolation after 4 days of anticoagulant and supportive treatments in the hospital. Clinical findings and initial laboratory results are shown in - Table $\mathbf{1}$.

Table 1 Initial clinical and laboratory findings of the family

\begin{tabular}{|c|c|c|c|c|c|}
\hline & Father & Mother & 23-year-old son & 21-year-old son & 15-year-old daughter \\
\hline Date of PCR positivity & April 2, 2020 & April 9, 2020 & April 7, 2020 & April 9, 2020 & April 11, 2020 \\
\hline Date of hospitalization & April 9, 2020 & April 9, 2020 & April 9, 2020 & April 9, 2020 & April 9, 2020 \\
\hline Fever & 39 & 38.3 & 37.8 & 37.5 & 37.8 \\
\hline$A B P$ & $138 / 85$ & $125 / 80$ & $130 / 80$ & $120 / 70$ & $120 / 80$ \\
\hline HR & 132 & 110 & 130 & 94 & 94 \\
\hline RR & 26 & 14 & 16 & 14 & 16 \\
\hline OS & 84 & 96 & 94 & 98 & 98 \\
\hline WBC & 6,810 & 6,610 & 4,810 & 5,600 & 6,600 \\
\hline Hemoglobin & 13.1 & 12.3 & 16.4 & 15.6 & 12.4 \\
\hline Neutrophil & 5,070 & 3,400 & 2,870 & 3,550 & 3,600 \\
\hline Lymphocyte & 1,290 & 2,800 & 1,560 & 2,000 & 3,000 \\
\hline Platelet & 221,000 & 416,000 & 139,000 & 318,000 & 214,000 \\
\hline Urea & 12 & 23 & 22 & 16 & 18 \\
\hline Creatinine & 0.79 & 0.68 & 0.97 & 0.98 & 0.67 \\
\hline $\mathrm{LDH}$ & 444 & 249 & 327 & 146 & 166 \\
\hline CRP & 10.04 & 0.77 & 23.94 & 4.6 & 2.4 \\
\hline Ferritin & 863 & 35.53 & 317.8 & 98 & 66 \\
\hline AST & 42 & 32 & 43 & 22 & 20 \\
\hline ALT & 52 & 22 & 35 & 24 & 24 \\
\hline D-dimer & 1.2 & 0.13 & 0.08 & 0.01 & 0.01 \\
\hline CT findings & $\begin{array}{l}\text { Bilaterally } \\
\text { involvement }\end{array}$ & $\begin{array}{l}\text { Bilaterally } \\
\text { involvement }\end{array}$ & $\begin{array}{l}\text { Bilaterally } \\
\text { involvement }\end{array}$ & $\begin{array}{l}\text { Bilaterally } \\
\text { involvement }\end{array}$ & $\begin{array}{l}\text { Bilaterally } \\
\text { involvement }\end{array}$ \\
\hline Need for ICU & Yes & No & Yes & No & No \\
\hline Follow-up duration & 10 & 7 & 7 & 4 & 4 \\
\hline
\end{tabular}

Abbreviations: ABP, arterial blood pressure; ALT, alanine aminotransferase; AST, aspartate aminotransferase; CRP, C-reactive protein; CT, computed tomography; HR, heart rate; ICU, intensive care unit; LDH, lactate dehydrogenase; OS, oxygen saturation; PCR, polymerase chain reaction; RR, respiratory rate; WBC, white blood cell. 

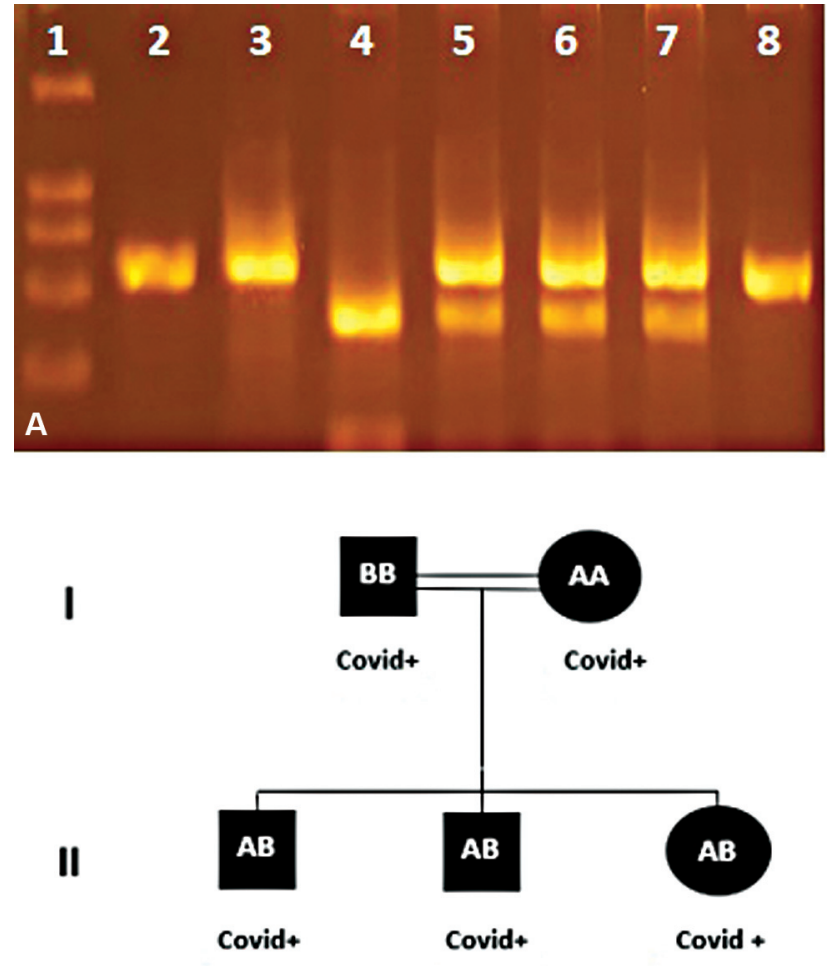

B

Fig. 1 (A) PCR-RFLP products of MBL2 (rs 1800450) polymorphism on $2 \%$ agarose gel. (B) Family pedigree. 1. Marker, 2/8. Nondigest PCR product, 3. Father/BB, 4. Mother/AA, 5. Son/AB, 6. Son/AB, 7. Daughter/AB (BB: homozygous mutant-gene expression negative, $A B$ : heterozygous mutant-gene expression decreased-1/10, $A A$ : homozygous normal-gene expression positive).

According to the results of MBL2 (rs1800450) variant analysis performed retrospectively, father had BB (homozygous mutant), mother $A A$ (homozygous normal) and the three children had $\mathrm{AB}$ (heterozygous mutant) genotypes (- Fig. 1).

\section{Discussion}

To the best of our knowledge, the COVID-19 family we have reported constitutes the first report in which MBL2 gene variants are shown. As a summary of studies which investigate the effect of the MBL2 genotype on gene expression, it was reported that MBL expression in the $A B$ genotype decreased by $1: 10$, while there was no expression in the BB genotype. ${ }^{7,9}$ In our previous study, it was revealed that patients with $B B$ genotype have a more severe clinical picture.

Clinical findings are supported by MBL2 gene polymorphisms in other studies. In a meta-analysis on severe acute respiratory syndrome coronavirus (SARS-CoV)-1, Middle East respiratory syndrome-related coronavirus, and SARSCoV-2, 22 out of 32 articles between January 2003 and June 2020 were found to be eligible for review. ${ }^{10}$ As a result of the analysis, it has been determined that MBL2 gene variants are effective in at least two studies. In another study, Zhang et al examined the frequencies of one mutation in codon 54 and three promoter polymorphisms in nt 550, 221, and four in 352 patients with SARS and 392 healthy controls by using PCR direct sequencing. ${ }^{11,12}$ In this study, codon 54 variant ( $r$ 1800450) ownership was associated with decreased MBL2 expression and SARS-CoV susceptibility. In another study, MBL2 gene polymorphisms and MBL serum levels were examined. ${ }^{12}$ The distribution of MBL2 gene polymorphisms was significantly different between SARS patients and the control group, the frequency of haplotypes associated with low or missing MBL serum levels was higher in SARS patients than in the control group. Serum MBL levels were also significantly lower in SARS patients than in the control group.

In the family who was the subject of our study, it is an expected finding that the father has a BB genotype and has the most severe clinical picture. It is thought that the most severe clinical picture after the father, unlike his other siblings, is seen in the 23-year-old son with multiple reasons: he is the first person to become positive after the father and was probably disadvantaged in terms of viral exposure and viral load compared with the other siblings. Because of the gender difference and more importantly, consanguineous marriage between parents, the effects of other possible recessive genes may also have created this difference. The fact that the 15-yearold daughter had the mildest clinical picture, and the disease is thought to be related to the latest PCR positivity and less viral load exposure with isolations. We would like to highlight again that the mother is normal and has a mild life.

\section{Conclusion}

As a result, $M B L 2$ gene polymorphism plays a very important role in terms of COVID-19 susceptibility and severe disease. The family, which makes up our case report, is the proof of this situation, and it contains important implications for host factors and COVID-19.

\section{Availability of Data and Materials}

The authors declare that data supporting the findings of this study are available within the referenced articles.

\section{Ethical Approval and Consent to Participate}

Ethical committee approval was received (Faculty of Medicine, Istanbul University, approval date and number: 21/05/2020-84539) and a written consent was obtained from all patients for both sampling and publishing. The experimental procedures were based on the Declaration of Helsinki and relevant institutional regulations.

\section{Funding}

None.

Conflict of Interest

None declared.

\section{References}

1 Cai Q, Chen F, Wang T, Luo F, Liu X, Wu Q, et al. Obesity and COVID19 Severity in a Designated Hospital in Shenzhen, China. Diabetes Care 2020;43(07):1392-1398 
2 Guan WJ, Ni ZY, Hu Y, Liang WH, Ou CQ, He JX, et al;China Medical Treatment Expert Group for Covid-19. Clinical characteristics of coronavirus Disease 2019 in China. N Engl J Med 2020;382(18): 1708-1720

3 Wu C, Chen X, Cai Y, Xia J, Zhou X, Xu S, et al. Risk factors associated with acute respiratory distress syndrome and death in patients with coronavirus disease 2019 pneumonia in Wuhan, China. JAMA Intern Med 2020;180(07):934-943

4 Jacobson S, Larsson P, Åberg AM, Johansson G, Winsö O, Söderberg S. Levels of mannose-binding lectin(MBL) associates with sepsis-related in-hospital mortality in women. J Inflamm (Lond) 2020;17:28

5 Best LG, Ferrell RE, Decroo S, North KE, Maccluer JW, Zhang Y, et al. Genetic and other factors determining mannose-binding lectin levels in American Indians: the Strong Heart Study. BMC Med Genet 2009;10:5

6 Eisen DP, Minchinton RM. Impact of mannose-binding lectin on susceptibility to infectious diseases. Clin Infect Dis 2003;37(11): 1496-1505

7 Medetalibeyoglu A, Bahat G, Senkal N, Kose M, Avci K, Sayin GY, et al. Mannose binding lectin gene 2 (rs1800450) missense variant may contribute to development and severity of COVID-19 infection. Infect Genet Evol 2021;89:104717

8 Sumiya M, Super M, Tabona P, Levinsky RJ, Arai T, Turner MW, et al. Molecular basis of opsonic defect in immunodeficient children. Lancet 1991;337;(8757):1569-1570

9 Madsen HO, Garred P, Kurtzhals JA, Lamm LU, Ryder LP, Thiel S, et al. A new frequent allele is the missing link in the structural polymorphism of the human mannan-binding protein. Immunogenetics 1994;40(01):37-44

10 Di Maria E, Latini A, Borgiani P, Novelli G. Genetic variants of the human host influencing the coronavirus-associated phenotypes (SARS, MERS and COVID-19): rapid systematic review and field synopsis. Hum Genomics 2020;14(01):30

11 Zhang H, Zhou G, Zhi L, Yang H, Zhai Y, Dong X, et al. Association between mannose-binding lectin gene polymorphisms and susceptibility to severe acute respiratory syndrome coronavirus infection. J Infect Dis 2005;192(08):1355-1361

12 Ip WK, Chan KH, Law HK, Tso GH, Kong EK, Wong WH, et al. Mannose-binding lectin in severe acute respiratory syndrome coronavirus infection. J Infect Dis 2005;191(10):1697-1704 